\title{
Study on the Isomerization Reaction of Turpentine Oil Catalyzed by the Acid-treated HangJin $2^{\#}$ Clay
}

\author{
Jie Zhang \\ College of Chemistry and Environmental Science \\ Inner Mongolia Normal University \\ Huhhot, China \\ e-mail:185640454@qq.com \\ Guanghua Shen \\ College of Chemistry and Chemical Engineering \\ Zhaoqing University \\ Zhaoqing, China \\ e-mail:994054380@qq.com \\ Wanzhuang Mai \\ College of Chemistry and Chemical Engineering \\ Zhaoqing University \\ Zhaoqing, China \\ e-mail:591531115@qq.com \\ Bing Liang \\ College of Chemistry and Chemical Engineering \\ Zhaoqing University \\ Zhaoqing, China \\ e-mail: 460945672@qq.com
}

\author{
Xiangying Hao* \\ College of Chemistry and Chemical Engineering \\ Zhaoqing University \\ Zhaoqing, China \\ e-mail:xyinghao@zqu.edu.cn
}

Zhiwei Li

College of Chemistry and Chemical Engineering Zhaoqing University

Zhaoqing, China

e-mail:390108522@qq.com

Shunhua Li

College of Chemistry and Chemical Engineering Zhaoqing University

Zhaoqing, China

e-mail:1359036484@qq.com

Ming Zhang

College of Chemistry and Chemical Engineering Zhaoqing University

Zhaoqing, China

e-mail:274778641@qq.com

\begin{abstract}
In order to reduce costs and improve the activity of catalyst in turpentine oil isomerization reaction, two solid acid catalysts (b and c) were prepared by using sulfuric acid and hydrochloric acid treated HangJin $2^{\#}$ clay (a), respectively. On the basis of sulfuric acid-treated HangJin $2^{\#}$ clay (b) as carrier, $\mathrm{SO}_{4}{ }^{2-} /$ HangJin $2^{\#}$ clay (d) and $\mathrm{PO}_{4}{ }^{3-} /$ HangJin $2^{\#}$ clay (e) catalysts were prepared by dipping sulfuric acid and phosphoric acid in catalyst $b$, respectively. Five catalysts (a, b, c, d and e) were characterized by TPD, TG-DTA and BET. Moreover, the isomerization reaction of turpentine oil catalyzed by a, b, c, d, and e were also investigated. The results revealed that the catalytic activities as follow: $b>c, e>d$.
\end{abstract}

Keywords- HangJin $2^{\#}$ clay; solid acid; catalyst; turpentine oil; isomerisation.

\section{INTRODUCTION}

The isomerization reaction of turpentine oil is one of the most important chemical reactions in turpentine deep processing, which usually catalyzed by solid acid catalyst [1], molecular sieve [2], clay[3], etc.. Solid acid catalysts show highly active in turpentine oil isomerization reaction, but there still exist some problems such as complicated preparation process, high cost and short service life. Although molecular sieve show large specific surface area, simple preparation and recycle, problems remain in terms of low selectivity and easy carbon deposition. In recent years, Clay has received widespread attention owing to their low price, high activity, recycle and simple preparation [4].

In recent years, it has been found that HangJin $2^{\#}$ clay shows high catalytic activities and as potential applications in catalysis[5]. Jingfang Wei et al. found that sulfuric acid and hydrochloric acid treated HangJin $2^{\#}$ clay show larger BET and more stability with the conversion of the esterification reaction up to $99 \%[6]$. Yuli Zhang and co-workers have reported a $\mathrm{SO}_{4}^{2-} / \mathrm{Fe}-\mathrm{Al}-$ activated clay catalyst with a yield of $45 \%$ after using in turpentine hydration reaction [7]. Limei Bai et al. prepared a $\mathrm{SO}_{4}^{2-} / \mathrm{SnO}_{2}$-HangJin $2^{\#}$ clay catalyst with the reaction conversion rate up to $99 \%$ [8]. However, so far work on the preparation of HangJin $2^{\#}$ clay catalysts and its application in the isomerization reaction of turpentine oil have not been reported. 
In this paper, we report the preparation, characterization and application of four new HangJin $2^{\#}$ clay base catalysts.

\section{EXPERIMENTAL}

\section{A. Preparation of Catalysts}

Activated clay: A certain amount of HangJin $2^{\#}$ clay was mixed with hydrochloric acid, sulfuric acid at solidliquid ratio of $1: 2.5(\mathrm{~g} / \mathrm{mL})$ and kept stirring and reflowing for 4 hours at $90^{\circ} \mathrm{C}$. The filter cake was washed by distilled water, and dried under $110^{\circ} \mathrm{C}$ for 3 hours and then triturated.

Prepared based on the impregnation method. The activated clay was mixed with sulfuric acid or phosphoric acid respectively at solid-liquid ratio of 1:5 $(\mathrm{g} / \mathrm{mL})$ and kept stirring and reflowing for 4 hours at room temperature. Filtration: filter cake in a drying box for drying, grinding and sieving. Then it was rubbed through a 100 mesh sieve, and calcinated for 3 hours in the muffle furnace at $350{ }^{\circ} \mathrm{C}$.

\section{B. Physical Measurements}

Thermogravimetric analyses (TGA) were performed on an automatic simultaneous thermal analyzer (DTG-60, Shimadzu) under air at a heating rate of $20^{\circ} \mathrm{C} / \mathrm{min}$ between ambient temperature and $800{ }^{\circ} \mathrm{C}$.

Infrared spectra were recorded $\left(4000-400 \mathrm{~cm}^{-1}\right)$ as $\mathrm{KBr}$ disks on a Shimadzu IR-8400 spectrometer.

$\mathrm{NH}_{3}$-TPD analysis was performed on multifunctional adsorption equipment, High purity nitrogen as the carrier gas, Ammonia is adsorbed gas, in $10^{\circ} \mathrm{C} / \mathrm{min}$ heating rate from room temperature up to $600^{\circ} \mathrm{C}$.

The analysis of BET using American Mike company production of ASAP-2010, samples under vacuum pretreatment to $423 \mathrm{~K}$, nitrogen adsorption in $77.35 \mathrm{~K}$ (Liquid nitrogen).

\section{Catalytic Reactions}

A mixture of turpentine oil $(10 \mathrm{~mL})$ and $3 \%$ of catalyst was stirred at $150{ }^{\circ} \mathrm{C}$ for 3 hours under air. After the reaction, the catalyst was separated by filtration. The filtrate was dried over $\mathrm{Na}_{2} \mathrm{SO}_{4}$ and filtered. The products were quantified by GC-MS analysis (Shimadzu GCMSQP5050A equipped with a $0.25 \mathrm{~mm} \times 30 \mathrm{~m}$ DB-WAX capillary column). The conversion and selectivity of the product (pinene) were calculated based on Area NormalizationMethod[9].

$$
\begin{aligned}
& \text { Conversiomf pinene }=\frac{\text { Variationof pinene }}{\text { Contentin raw materialpinene }} \times 100 \% \\
& \text { Campheneselectivity }=\frac{\text { Camphenecontent }}{\text { The conversion rate of pinene }} \times 100 \%
\end{aligned}
$$

\section{RESULTS AND DISCUSSIONS}

\section{A. Turpentine Isomerization reaction catalysis.}

The result of turpentine isomerization reaction catalyzed by three different catalysts (a, b and c) was shown in Table 1. From the table 1, compared to HangJin $2^{\#}$ clay (a), the catalytic activities of acid treated HangJin $2^{\#}$ clay (b and c) were obviously improved with the conversion of pinene up to $99.09 \%$ and $100 \%$, respectively. Moreover, the BET of $\mathbf{b}$ and $\mathbf{c}$ were also significantly improved, up to 126.58 and $146.54 \mathrm{~m}^{2} / \mathrm{g}$, respectively. Compared to a, the principal product (camphene) catalyzed by $\mathbf{b}$ and $\mathbf{c}$ up to 35.75 and $32.41 \%$, respectively. In summary, the acid treated HangJin $2^{\#}$ clay (b and c) show larger BET and higher catalytic activity than a maybe due to the pore structure of $\mathbf{b}$ and $\mathbf{c}$ were opened after acid treatment, which causing the catalyst and the solution full contact. However, catalyst $\mathbf{b}$ shows higher activity than c with higher yield of principal product and lower yield of by-products.

TABLE I. THE RESULTS OF REACTION CATALYZED BY ACID

\begin{tabular}{ccccc}
\multicolumn{5}{c}{ TREATED HANGJIN $2^{\#}$ CLAY } \\
\hline Sample & $\begin{array}{c}\text { BET(m } \\
\text { /g) }\end{array}$ & $\begin{array}{c}\text { Conversion of } \\
\text { pinene(/\%) }\end{array}$ & \multicolumn{2}{c}{$\begin{array}{c}\text { The selectivity of } \\
\text { isomerization(/\%) }\end{array}$} \\
\cline { 4 - 5 } a & & $\begin{array}{c}\text { Camphe } \\
\text { ne }\end{array}$ & Others \\
\hline b & 62.62 & 13.98 & 55.60 & 44.40 \\
c & 126.58 & 99.09 & 40.58 & 59.42 \\
\hline
\end{tabular}

(a)HangJin $2^{\#}$ clay (b)sulfuric acid treated HangJin $2^{\#}$ clay (c)hydrochloric acid treated HangJin $2^{\#}$ clay

The TPD spectra of catalysts $(\mathbf{a}, \mathbf{b}, \mathbf{c})$ are shown in Fig. 1., the desorption peak of the weak acid sites move to the high temperature after treating the HangJin $2^{\#}$ clay using acid. Compared to hydrochloric acid treated HangJin $2^{\#}$ clay, which the stripping peak of weak/strong acid center move to $200^{\circ} \mathrm{C} / 520^{\circ} \mathrm{C}$, the sulfuric acid treated HangJin $2^{\#}$ clay appeared in $125^{\circ} \mathrm{C} / 510^{\circ} \mathrm{C}$. The results reveal that the acidity of the weak acid will be improved after acid treatment of HangJin $2^{\#}$ clay. Moreover, increase the acid content of the weak acid center of the catalyst to help the turpentine isomerization reaction.

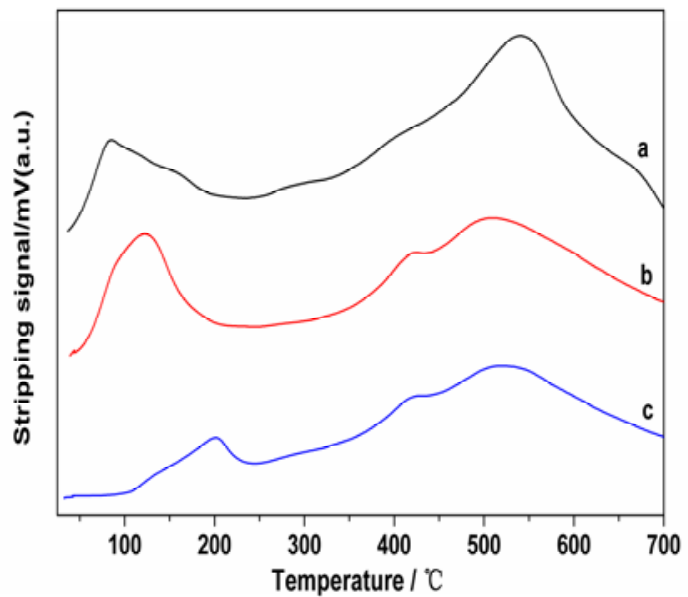

Figure 1. The TPD spectra of acid treated HangJin $2^{\#}$

clay
(a)HangJin $2^{\#}$ clay (b)sulfuric acid treated HangJin $2^{\#}$ clay (c)hydrochloric acid treated HangJin $2^{\#}$ clay

The TG curves of catalysts $(\mathbf{a}, \mathbf{b}, \mathbf{c})$ are shown in Fig. 2. All of three catalysts show two weight loss steps. The first corresponding to the release of adsorbed water and crystal water is observed from $25-200^{\circ} \mathrm{C}$. Then weightloss step occurred between $400-800^{\circ} \mathrm{C}$ which corresponds to the release of the load acid. The weightlessness ratio of 
b larger than c, indicates that the acid load of $\mathbf{b}$ higher than $\mathbf{c}$. It has been found that the acid load content play an important role in the number and acid strength of catalysts, which are in good agreement with the Table 1. However, catalyst a performs low catalytic activity is not agree with the high weight-loss between $400-800^{\circ} \mathrm{C}$, which the weight-loss mainly from the surface of the acid load of catalyst. Thus, the acid strength of catalysts is one of the main reasons to affect the activity of catalyst. Moreover, the reaction activity of catalysts is not only related with the catalyst acidity, but also related to the distribution of acid sites. Meanwhile, catalyst activity strongly depends on the weak center, especially when the catalysts were used in the isomerization reaction of turpentine [10].

The FT-IR spectra of catalysts $(\mathbf{a}, \mathbf{b}, \mathbf{c})$ are shown in Fig. 3. In the IR spectrum, the bands at $3600 \mathrm{~cm}^{-1}$ may be due to the $v(-\mathrm{OH})$ stretching vibrations, the bands at $3420 \mathrm{~cm}^{-1}$ may be due to the $v\left(\mathrm{H}_{2} \mathrm{O}\right)$ stretching vibrations. After the acid treated HangJin $2^{\#}$ clay, the bands of the $v\left(\mathrm{Fe}_{2} \mathrm{O}_{3}\right) \quad$ stretching vibrations at $1460 \mathrm{~cm}^{-1}$ was disappeared. The characteristic peaks between $1020 \mathrm{~cm}^{-1}$ and $1150 \mathrm{~cm}^{-1}$ are associated with the solid super acid. After the acid treated agent, the strength of characteristic peaks were increased. The characteristic peaks of $\mathbf{b}$ catalyst were stronger than a and c catalyst, which indicated that the $\mathbf{b}$ catalyst performs superior activity.

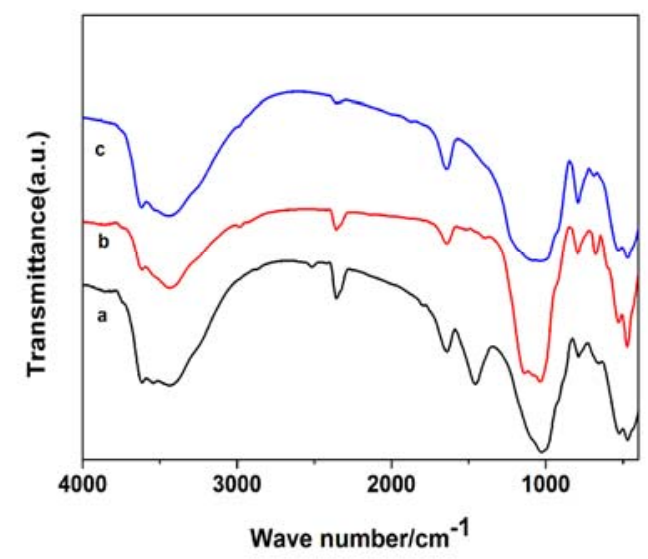

Figure 3. The FT-IR spectra of acid treated HangJin $2^{\#}$ clay

(a)HangJin $2^{\#}$ clay (b)sulfuric acid treated HangJin $2^{\#}$ clay (c)hydrochloric acid treated HangJin $2^{\#}$ clav

\section{B. The effects of Acid Dipping Activated Clay of Turpentine Isomerization reaction.}

The result of turpentine isomerization reaction catalyzed by two different catalysts ( $\mathbf{d}$ and e) was shown in Table 2.

From the Table 2, compared to catalyst $\mathbf{b}$, the catalytic activities of the acid dipping $\mathrm{SO}_{4}^{2-} /$ activated clay (d) and acid dipping $\mathrm{PO}_{4}^{3-} /$ activated clay (e) show low conversion of pinene (17.00\% and $28.53 \%$ ) and low BET (78.87 and $9.80 \mathrm{~m}^{2} / \mathrm{g}$ ), which maybe due to the pore structure were loaded by acid and reduce the BET of $\mathbf{d}$ and $\mathbf{e}$. The results reveal that the BET play an important role in catalytic activities.

TABLE II. EFFECTS OF ACID DIPPING ACTIVATED CLAY FOR TURPENTINE ISOMERIZATION

\begin{tabular}{|c|c|c|c|c|}
\hline \multirow[t]{2}{*}{ Sample } & \multirow[t]{2}{*}{ BET(m²/g) } & \multirow{2}{*}{$\begin{array}{c}\text { Conversion } \\
\text { of } \\
\text { pinene }(/ \%)\end{array}$} & \multicolumn{2}{|c|}{$\begin{array}{c}\text { The selectivity of } \\
\text { isomerization }(/ \%)\end{array}$} \\
\hline & & & Camphene & Others \\
\hline b & 126.58 & 99.09 & 40.58 & 59.42 \\
\hline d & 78.87 & 17.00 & 57.85 & 42.15 \\
\hline e & 9.80 & 28.53 & 34.76 & 65.24 \\
\hline
\end{tabular}

(b) sulfuric acid treated HangJin $2^{\#}$ clay; (d) $\mathrm{SO}_{4}^{2-}$ /activated clay; (e) $\mathrm{PO}_{4}^{3-} /$ activated clay

The TG curves of catalysts $(\mathbf{b}, \mathbf{d}, \mathbf{e})$ are shown in Fig. 4. All of three catalysts show two weight loss steps. The first corresponding to the release of adsorbed water and crystal water is observed from $25-200^{\circ} \mathrm{C}$. Then weightloss step occurred between $400-800^{\circ} \mathrm{C}$ which corresponds to the release of the load acid (obsd. $2.5 \%, 12.7 \%$ and $0.71 \%$ ). Too much acid were loaded in catalyst $\mathbf{d}$, result in the acid coated in the surface of catalysts and reduce the catalytic reactivity after high-temperature roasting[11]. The low weight-loss of catalyst e relate to the phosphor acid concentration and volume. It has been found that small amount of phosphoric acid or excessive amount of phosphoric acid were used will make the BET and catalytic activity decrease. On the basis of above mention, the amount of phosphoric acid plays a crucial role in catalytic activity. 


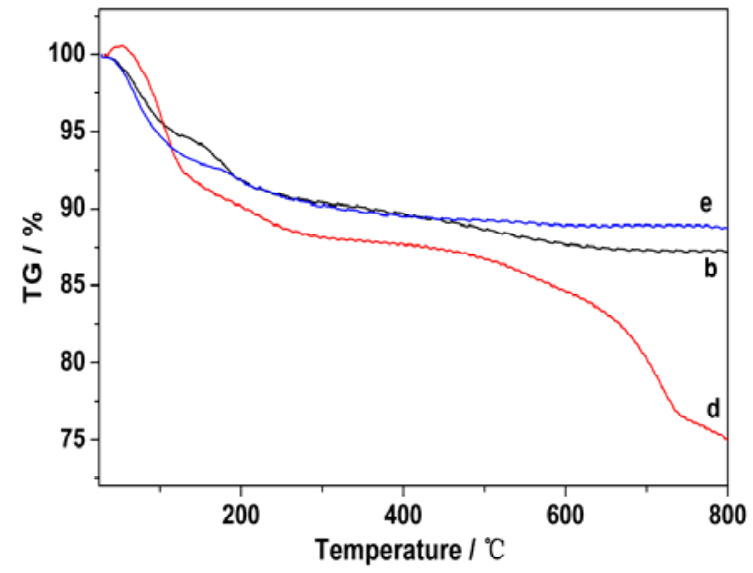

Figure 4. The TG curves of three different catalysts (b) sulfuric acid treated HangJin $2^{\#}$ clay (d) $\mathrm{SO}_{4}^{2-} /$ activated clay $(\mathbf{e}) \mathrm{PO}_{4}^{3-} /$ activated clay

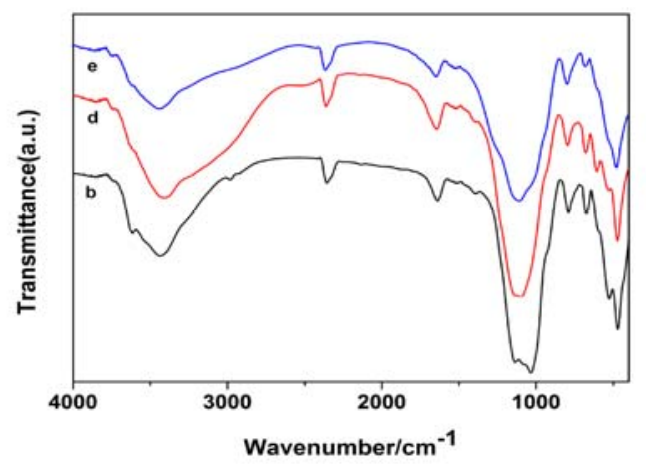

Fig.5. The FT-IR spectra of three different catalysts (b)sulfuric acid treated HangJin $2^{\#}$ clay (d) $\mathrm{SO}_{4}^{2-}$ /activated clay (e) $\mathrm{PO}_{4}^{3-} /$ activated clay

The FT-IR spectra of catalysts $(\mathbf{b}, \mathbf{d}, \mathbf{e})$ are shown in Fig. 5. In the IR spectrum, the bands at $1400 \mathrm{~cm}^{-1}$ may be due to the $v(\mathrm{~S}=\mathrm{O})$ stretching vibrations. The characteristic peaks between $1050 \mathrm{~cm}^{-1}$ and $1150 \mathrm{~cm}^{-1}$ are associated with the solid super acid. After the acid dipping agent, the strength of characteristic peaks between $1050 \mathrm{~cm}^{-1}$ and $1150 \mathrm{~cm}^{-1}$ were reduced. The characteristic peaks of $\mathbf{d}$ catalyst were stronger than e catalyst, which indicated that the d catalyst performs superior activity. The characteristic peaks of $\mathbf{b}$ catalyst were stronger than $\mathbf{d}$ catalyst, which indicated that the $\mathbf{b}$ catalyst performs superior activity.

\section{CONCLUSIONS}

In summary, we have successfully prepared four different catalysts based on HangJin $2^{\#}$ clay and were used in the isomerization reaction of turpentine, with the conversion of pinene up to $99 \%$. The results reveal that the acid play an important role in catalytic activity. Moreover, the acidity of the weak acid sites was increased will improved the yield of the camphene main product.

\section{ACKNOWLEDGEMENTS}

This work was financially supported by High level Talents Foundation in Colleges and Universities of Department of Education of Guangdong Province (503031) and the Open Project of Key Lab Adv Energy Mat Chem (Nankai Univ) (KLAEMC-OP201201).

\section{REFERENCES}

[1] Li Zhang, Lin Wang \& Jianmin Chen. Research on $\mathrm{S}_{2} \mathrm{O}_{8}^{2-} / \mathrm{ZrO}_{2}$ solid super acid. Chem J. Chin Univt, 1, pp. 116-119,2000.

[2] Na Chang, Xiangwen Zhang \& Li Wang. Study on Preparation of pinene biomass high-density fuel for catalytic acidic mesoporous molecular sieve. Chem. Cat. Chem, 2012.

[3] Fei Cha,Xiaoru Ma \& Haobin Chen. Montmorillonite catalytic hydrogenation of carbon dioxide synthesis of dimethul ether. Renewable Energy, 31(3), pp.81-85,2013.

[4] Fei Cha,Jingyun Wang. $\mathrm{SO}_{4}{ }^{2-} / \mathrm{MxOy}$ solid super acid modification progress. Chenical and Glue, 32, pp.42-45,2010.

[5] Yanlin Liu. The preparation and application of $\mathrm{SO}_{4}^{2-}$ HangJin $2^{\#}$ Clay. J. Inner Mongo. Norm. Univt, pp. 31-32,2008.

[6] Jingfang Wei, Xiangying Hao \& Peng Yan. Effect of different acid treatment on the catalytic properties of $\mathrm{SO}_{4}{ }^{2-} / \mathrm{HangJin} 2^{\#}$ Clay. J. Inner Mongo. Norm. Univt, 39(4), pp. 401-404, 2010.

[7] Yuli Zhang, Xiangying Hao \& Cui Zhang. Application of $\mathrm{SO}_{4}{ }^{2-}$ /Al-Fe-activated solid scid catalyst prepared by cross-linking method. Appl. Mech. Mater, 448-453, pp. 2929-2932, 2014.

[8] Limei Bai, Xiangying Hao \& Haifu Guo. The Solid acid of $\mathrm{SO}_{4}{ }^{2-} / \mathrm{SnO}_{2}$-HangJin $2^{\#}$ Clay to Catalytic synthesis of terpinyl acetate. J. Inner Mongo. Norm. Univt, 40(3), pp.278-282,2011.

[9] Guizhen Li, Xiongmin Liu \& Li Ma. Study of turpentine oil catalyzed by solid acids isomerisation. Appl. Chem., 36, pp.121-123,2007.

[10] Ning li, Peng Wang \& Xifu Jiang. Effect of $\mathrm{ZrO}_{2}$ content on $\mathrm{SO}_{4}{ }^{2-} / \mathrm{TiO}_{2} / \mathrm{ZrO}_{2}-\mathrm{Al}_{2} \mathrm{O}_{3}$ catalyzed alpha pinene isomerization performance. J. Guilin Univt, 30(1), pp.103-107,2010.

[11] Hua Song, Sai Xu, Quanfu Liu. Preparation conditions on the $\mathrm{Pt}-\mathrm{SO}_{4}{ }^{2-} / \mathrm{ZrO}_{2}-\mathrm{Al}_{2} \mathrm{O}_{3}$ isomerization performance impact. Chem. Eng., 4(38), pp.36-39,2010. 